\title{
AMBIGUOUS INTERVENTION AT MOCENIGO: BRIGITTE NIEDERMAIR
}

\section{Leoni Schmidt}

Julie Perini writes in "Art as Intervention: A Guide to Today's Radical Art Practices" (2010) about some of those artists or groups of artists who "use creative energy to transform immediate social realities and construct meaningful experiences that happen in the streets, museums and galleries, domestic spaces, and any location where oppressive authoritarian forces reign."' According to her, they create alternate realities as rehearsal spaces or laboratories where "active imaginations, combined with active participation, become critical tools for co-creating social systems."

Extant examples of art as intervention hail from previous ages; it is not just a recent phenomenon, despite the fact that the practice has gained an identity, a name and critical acclaim only in the last century or so. One could argue, for example, that Early Christian images of fish as a symbol of Christ were interventions on the walls of catacombs against the oppressive regime of the Roman Empire. Or, that sexualised images on the misericordia of medieval cathedrals were interventional devices intended to offset the rigid spiritual dogma of the church. Closer to our time, Gustave Courbet's private one-man exhibition of his own work staged during the 1855 Universal Exposition, thereby setting himself against the closed system of the Salon of the French Academy, might be interpreted as an interventional act of revolutionary impact.

Still closer in time, Dada artists, motivated early in the twentieth century by the chaos of the First World War, staged public interventions aimed at unmasking the rational tenets of the Enlightenment. Their 'heirs,' among whom were the Situationists of the 1960s, took to the streets of Paris in an effort to critique the alienation caused by advanced capitalism. They created 'situations' for expediting experiences outside of the capitalist system.

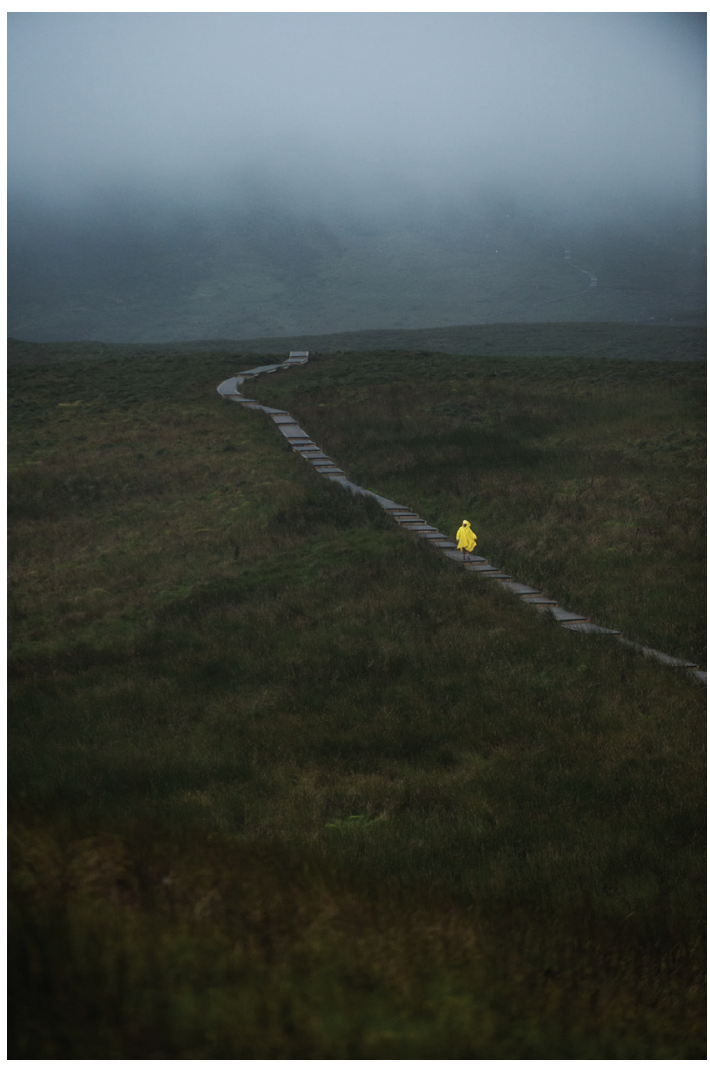

Figure I. Suzanne Lacy, Across and In-Between: The Yellow Line, Cuilcagh Mountain, 2018.

Photograph: Helen Sloan SMPSP and Ross Mulhall. Image courtesy of the artist. 


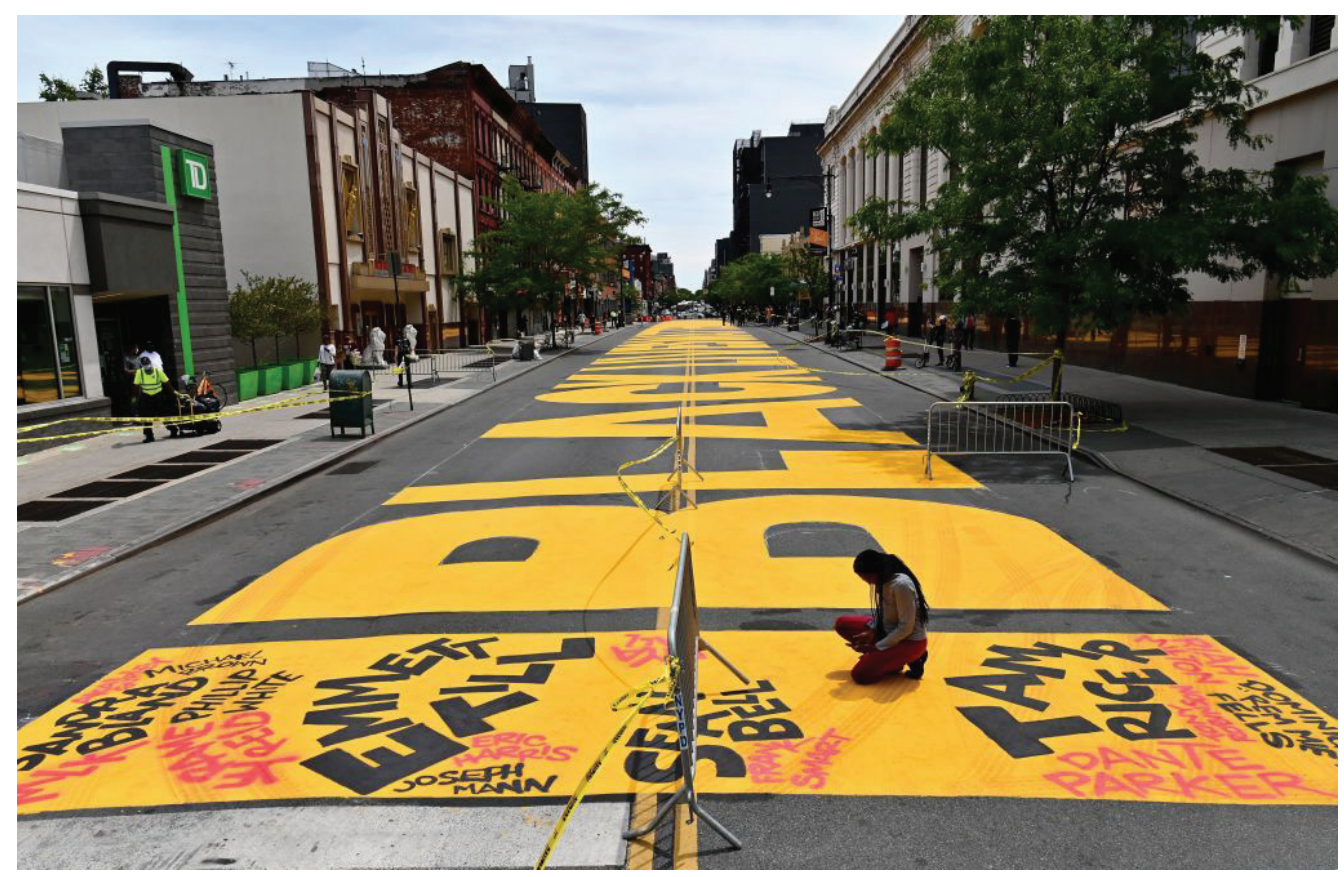

Figure 2. Fulton Street Mural, Brooklyn, New York.

Documentation of the Black Lives Matter mural, 2020.

Photograph: Angela Weiss/Getty Images.

More recently, artists such as Mierle Laderman Ukeles and Fred Wilson have staged interventions, respectively drawing attention to the 'invisible' labour needed to prop up public institutions like museums, and to the invisibility of the history of slavery in the United States of America. Laderman Ukeles performed an intervention in 1973 titled Washing/Tracks/Maintenance Outside on the steps of the Wadsworth Athenaeum in Hartford, Connecticut. She literally washed the steps leading into the main entrance of the museum, thereby drawing attention to those labours many take for granted and delegate to the hours of the night. African American Fred Wilson's "Mining the Museum" exhibition, held at the Maryland Historical Society in 1992-93, was a clear critique of colonisation through sets of juxtapositions. One of these showed ornate silverwork of obvious European provenance, with rusted slave shackles intervening among them in the same vitrine.

These are well-known examples; there are many more. What they have in common is a clear target and a clear message: critiquing authority and suggesting an alternative way of seeing or experiencing. In recent years, interventionist practices have included Suzanne Lacey's Across and in-Between (2018), about the border between Northern Ireland and the Republic of Ireland. Participants explored a line as border and how this affected their lives, (Figure I). Their painstaking efforts to remain on the thin line brought its real-life stressful effects into sharp focus.

During 2020, the Black Lives Matter movement led to many interventions in public spaces. In one of these, many people worked together to create a giant-sized horizontal painting on a street in New York. Nobody in the vicinity could ignore the work. It spoke loudly on a large scale of the outrage felt following the violent death of George Floyd and other African Americans before him.

Art as intervention also looms large at the Venice Biennale, where the whole city lends itself to this kind of practice. Venice has many museums, galleries, small buildings, street corners, alleyways and other public sites - such as palazzi 
- that can be mined as potential spaces for interventionist tactics. The notion of "tactics" reminds one of Michel de Certeau's distinction between this concept and the concept of "strategies." In The Practice of Everyday Life (1988), de Certeau characterises "strategies" as actions deployed by institutions and governments to regulate the lives of citizens, while "tactics" suggest activities aimed at undermining, subverting or changing these regulatory moves. ${ }^{3}$ Art interventions mostly fall within the scope of "tactics" as deployed in de Certeau's vocabulary.

As suggested above, Venice is a city uniquely positioned for interventional tactics. In 2019, I visited the Venice Biennale and - following the example of the Situationists - practiced the art of the dérive, ${ }^{4}$ walking through the urban environment in an unplanned way to encounter what it has to offer, relinquishing expectations and responding to the infiltration of this ancient city by contemporary arts practices, willing to be surprised and for assumptions to be questioned.

Walking through Venice during the Biennale, one becomes aware of the city as a stage for dialogue happening between two main characters: the old architecture and the new infiltrations into its very fabric - into spaces, up ceilings, through passageways, underneath walkways, poised on ledges, written on bridge stanchions, reflecting in the water of the canals. Some of the interventions are hidden from the casual glance behind heavy doors, seemingly impenetrable to the casual eye.

On my last day in Venice during 2019, I went for a short stroll to farewell the narrow alleys, canals, bridges and buildings of my beloved Santa Croce, the Sestiere where I have stayed so many times in my life. Walking around, I encountered a building that had escaped my notice after all this time: the Palazzo Mocenigo. In order to arrive at the crux of this article, I have to share information about this building.

The Palazzo Mocenigo's official website ${ }^{5}$ tells one that the building is of Gothic origin, and was extensively rebuilt at the beginning of the seventeenth century to become the residence of the San Stae branch of the Mocenigo family; seven members of the family were Venetian doges between 1414 and 1778. "The family also supplied the State with numerous procurati (administrators), ambassadors, sea and land captains, clergymen, and men of letters." 6 The last descendent of the family bequeathed the palazzo to the city of Venice in 1945 to become a museum. It was opened to the public in 1985 and has since housed vast collections of fabric and costumes, displaying the expertise and luxury associated with these crafts in Venice over many centuries. Male dress dominates, with one room dedicated, for example, to the waistcoat, crafted from exquisite silk and embroidered fabrics. A relatively new section is devoted to perfume, "highlighting the key role the city played in the origins of this aesthetical, cosmetic and entrepreneurial custom."'

Among these riches, the visitor is struck by paintings of the city, along with the many portraits of important male members of the Mocenigo family, often portayed in large scale and clothed in rich fabrics and other adornments, such as jewelry pieces and elaborate shoes. Wealth, status, entrepreneurship, trade in luxury items and an appeal to the visual, haptic and olfactory senses emanate from the paintings, brocade and satin wallpapers, dressed mannequins, objects in vitrines and perfume pipettes of the Palazzo Mocenigo. It is into this carefully curated manifestation of a strategic positioning of cultural capital ${ }^{8}$ that artist Brigitte Niedermair chose to insert her interventionist tactics as part of the 2019 Venice Biennale.

Brigitte Niedermair was born and now lives in Italy after studying and working in Miami, New York and Los Angeles, often in the context of big-city fashion photography. She works with a $4 \times 5$ large-format camera to construct large-scale images that seem to hover between the world of fashion photography and critique of its effects - for example, female exploitation, the promotion of consumerism and body stereotypes. Charlotte Cotton, who curated Niedermair's exhibition in the Palazzo Mocenigo for the Venice Biennale in 2019, wrote: "There is a cultural strength to her character ... She's pro-women, and she is genuinely speaking to and for women. That remains a prized and underrated quality within fashion."' 
Niedermair's exhibition in the Palazzo Mocenigo fulfilled no single interventionist agenda. Rather, a number of tactics were deployed. One of these involved removing some of the many historical paintings to create space for the contemporary photographs, similar in scale to the large paintings. A strong contemporary presence infused the rooms of the palazzo. Secondly, the differentiation between representational painting and painterly photography comes into play: two media vying for our attention, with reference to a now approximately two-centuries-old enmity and dialogue. Thirdly, the photographs with their strong luxe aesthetic hold their own within the highly wrought, sophisticated interior of the Mocenigo. One can only be impressed by the visual strength with which Niedermair pulled these tactics off.

The tactic of inserting a strong feminine presence into the male gendered context of the Mocenigo is where Niedermair's intervention becomes ambiguous and even troubling in some instances. In this regard, one can differentiate between three dimensions of the work: one focuses on the beauty and strength of the female body and its adornment; the second seems to play into the misogyny of extreme fashion demands; while a third dimension offers up the female body to the male gaze, thereby buying into the patriarchy it seemed intended to confront. Three sets of images make these distinctions clearer.

\section{CORSET}

Niedermair's large photograph in her exhibition titled Fashion and Me (2019) shows the torso of a woman clad in tight grey lace in the front of the picture plane. ${ }^{10} \mathrm{It}$ is a confronting image of strength and sophistication. The intricacies of lace embroidery echo the long history of fabric arts in the city of Venice and bring a sense of female resilience to the room. At the same time, it provides a contrast to the exhibition of male waistcoats just around the corner in the palazzo. As an exhibit of a garment, more than of a particular body in this context, the cut-off neck and face feel less of an indignity than might otherwise be the case. The exquisite beauty of the lace garment is offset by its rigid formality.

Niva Piran writes about practices of "physical corseting" and their impact on "mental corseting" in her book Journeys of Embodiment at the Intersection of Body and Culture (2017)." She explores the ways in which girls are expected to "rein in" their bodies and how this expectation continues into adulthood, being deeply entrenched in the world of fashion. The trope of the 'corset' lies at the heart of this process. Our garment at the Mocenigo functions both as a counterfoil for the male waistcoats and as an embodiment of a restraining aspect of European culture. However, the history of the corset enables a more complex reading. The Victoria and Albert Museum publication, The Corset in Late Twentieth Century Fashion, tells us that

"The corset is full of paradoxes ... [it] bears an everlasting sexual attraction: it glorifies, underlines, exacerbates and idealises the female form. It has evolved esthetically and symbolically ... from constriction to power, from lingerie to armour."12

\section{STILETTO}

This work dwarfed the furniture at the Mocenigo. A pair of red stilettos were seen from behind to emphasise the heels. The men strolling past seemed to take them for granted - no big shock at seeing them so enlarged and in this place; just part of life for them, maybe. ${ }^{13}$ However, the stiletto brings with it a loaded, often shocking, history. Maude Bass-Krueger and Alice Cary alert us to this in their Vogue article, "Everything You Ever Wanted to Know About the Stiletto" (2020). Before the high heel became exclusively associated with the female - and drag - domain, in the seventeenth century Louis XIV wore them to express his authority. Closer to our time, Marilyn Monroe wore stilettos to enable her sexy walk, a walk that prevented her from moving freely. No easy dérive for her through the streets. "Fetishistic aspects of the stiletto have gained the heel a reputation as a powerful tool of seduction ... [but also of] violence and power;" it can also "represent empowerment, liberation, and the playful side of fashion."'14 
Niedermair's large photograph memorialises the stiletto. One could read it in many ways: as a monument to and a celebration of women's resilience, or as a sexual fetish; as empowerment or disempowerment of women; as exquisitely crafted objects of frivolity, or as the latest example of a very long history of women's bondage through shoes, stretching back to Chinese foot binding practices. Amanda Foreman's Smithsonian article, "Why Footbinding Persisted in China for a Millennium," suggests eerie similarities with what we know about the stiletto: "footbinding was imbued with erotic overtones ... every aspect of women's beauty was intimately bound up with pain ... social forces then subjugated women [who could hardly move]."15

\section{BOUDOIR}

A large photographic nude intervenes in a Mocenigo space. ${ }^{16}$ Wallpaper with its golden sheen, satin upholstery, a silk tablecloth and a splendid blue-and-white Chinese vase together signal opulence and luxury, enhanced by the subtle scent of perfume from adjacent rooms. The setting suggests the interior of a boudoir. Critsey Rowe's book Boudoir Photography $(201)^{17}$ provides 'how to do' insights into this genre. We learn that this kind of photography is aimed at providing potential husbands with a portfolio of sexualised images in the intimate setting of a lounge or other domestic spaces.

Ilya Parkins adopts a more analytical stance in a chapter titled "Becoming in the Eyes of Others: The Relational Gaze in Boudoir Photography," included in editors Morna Laing and Jacki Wilson's Revisiting the Gaze: The Fashioned Body and the Politics of Looking (2020). Parkins argues that the genre should no longer be interpreted through the binary of powerless female and powerful male, but rather through a more complex understanding of identity formation. The female subject knowingly invites the gaze through which her sexual agency is confirmed. Parkins writes: "the subject comes to be, and is transformed, in visual relation."'8 In a part of her chapter she calls "Boudoir Photography and Confident Selfhood Narrative," Parkins quotes Angela McRobbie's dictum, "women have been endow[ed] with capacity." ${ }^{9}$

Niedermair's nude was placed in a room within the Mocenigo, its very presence transforming the space into a boudoir context and figuring the genre of presentation as boudoir photography. The 'decapitated' and thus depersonalised nude seen from behind rings alarm bells for a viewer schooled in Laura Mulvey's feminist critique of the gaze. ${ }^{20}$ Is Niedermair playing into the long history of erotic nudes positioned for the lingering male gaze? Or, is she foregrounding the capacity and agency of women today to create their own transformative visual relationships, as Parkins and McRobbie might argue?

As in the case of CORSET and STILLETO, the trope of BOUDOIR leaves the viewer with an experience of ambiguity, perhaps rightly so in our era wherein feminism is no longer predicated on binaries, but rather on complex perspectives that highlight context and point of view over essentialised and dogmatic categories. In Reclaiming the F Word: Feminism Today (2013), authors Catherine Redfern and Kristin Aune discuss the prospects for "liberated bodies" in our time. ${ }^{21}$ One could read this as a counterfoil to Michel Foucault's famous focus on "docile bodies"22 in the last century.

Finally, a detail from Niedermair's nude intervened in my reflections at the time in Venice. She wears a body stocking that emphasises her erotic behind while simultaneously protecting and bringing her body right down to earth: a woman photographed after getting dressed in an everyday garment. The pantyhose acts as a disruption, its everyday banality interfering with the idealisation and sexualisation of the body. This small detail underscores the creative ambiguity of Niedermair's intervention at the Mocenigo. 
Leoni Schmidt (ORCID ID: https://orcid.org/0000-000I-7/85-7800) is Director: Research \& Postgraduate Studies at Otago Polytechnic and DCE: Academic at the Otago Polytechnic Auckland International Campus. She is an art historian by training and writes frequently on aspects of the Venice Biennale, an event she has visited regularly since 2004.

I Julie Perini, "Art as Intervention: A Guide to Today's Radical Art Practices," in Uses of a Whirlwind: Movement, Moments, and Contemporary Radical Currents in the United States, eds Team Colors Collective (Chico, CA: AKA Press, 20 I0), I83-97, at I83.

2 Ibid., 196.

3 See Michel de Certeau, The Practice of Everyday Life, trans. Steven Rendall (Berkeley: University of California Press, 1980/20 I I).

4 See Guy Debord, "Theory of the Dérive," Les Lèvres Nues, 9 (November 1956), trans. Ken Knabb, http://www.cddc.vt.edu/ sionline/si/theory.html (accessed 4 June 202I).

5 See Fondazione Musei Civici di Venezia, Palazzo Mocenigo, https://mocenigo.visitmuve.it/wp-content/uploads/2016/06/ Museum-of-Palazz-Mocenigo-short-ENG.pdf (accessed 4 June 2021).

6 ibid., I.

7 Ibid.

8 Pierre Bourdieu and Jean-Claude Passeron coined the phrase "cultural capital" in 1973 in a paper titled "Cultural Reproduction and Social Reproduction," further developed in Bourdieu's 1979 book Distinction: A Social Critique of the Judgement of Taste (Cambridge, MA: Harvard University Press, 1979/84). According to Bourdieu, one type of cultural capital is embodied in objects that signify status, wealth and activity, such as educational pursuits under which one could class entrepreneurship.

9 Charlotte Cotton, quoted in Tom Seymour, "Brigitte Niedermair Puts Fashion in Focus at Venice Retrospective," Wallpaper, 9 May 2019, https://www.wallpaper.com/fashion/brigitte-niedermair-profile.

I0 Brigitte Niedermair, Fashion and Me, Palazzo Mocenigo,Venice, 2019. See image at https://www.wallpaper.com/fashion/brigitteniedermair-profile\#0_pic_5

II Niva Piran, Journeys of Embodiment at the Intersection of Body and Culture: The Developmental Theory of Embodiment (London: Elsevier Academic Press, 2017).

12 Victoria and Albert Museum, The Corset in Late Twentieth Century Fashion (London:Victoria and Albert Museum, 20 I6), n.p.

13 Brigitte Niedermair, Fashion and Me, Palazzo Mocenigo,Venice, 20 19. See image at https://www.wallpaper.com/fashion/brigitteniedermair-profile\#0_pic_9 and in context at the Palazzo Mocenigo http://contessanally.blogspot.com/2019/06/venice-notonly-biennale-museo-di.html

I4 Maude Bass-Krueger and Alice Cary, “Everything You Ever Wanted to Know About the Stiletto," Vogue, 24 March 2020,4 \& 8.

I5 Amanda Foreman, "Why Footbinding Persisted in China for a Millennium," Smithsonian Magazine, February 20 I 5, https://www. smithsonianmag.com/history/why-footbinding-persisted-china-millennium- | 8095397|/ (accessed 4 June 202I).

16 Brigitte Niedermair, Fashion and Me, Palazzo Mocenigo,Venice, 2019. See image at https://www.wallpaper.com/fashion/brigitteniedermair-profile\#0_pic_7 and for context The Palazzo Mocenigo, the setting for the Brigitte Niedermair exhibition, features fabrics on the wall and the upholstery by Rubelli. Photo: Giacomo Santini at https://www.architecturaldigest.com/story/rubellicontemporary-artists-venice-biennale-projects

17 Critsey Rowe, Boudoir Photography (London: Hachette, 201 I).

I8 Ilya Parkins, "Becoming in the Eyes of Others:The Relational Gaze in Boudoir Photography," in Revisiting the Gaze:The Fashioned Body and the Politics of Looking, eds Morna Laing and Jacki Wilson (London: Bloomsbury, 2020), I0 I-23, at I 03.

19 Angela McRobbie, “'Top Girls?' Young Women and the Post-Feminist Sexual Contract," Cultural Studies, 21:4-5 (2007), 7I8737, at 722 .

20 See Laura Mulvey, Visual and Other Pleasures (New York: Palgrave, 1989).

21 Catherine Redfern and Kristin Aune, Reclaiming the FWord: Feminism Today (London: Zed Books, 2013). See Chapter One.

22 See Michel Foucault, "Docile Bodies," in Discipline and Punish, trans. Alan Sheridan (New York: Pantheon, 1977). 